\title{
EUTIFRÓN
}

PLATÓN

Introducción del traductor

"Pero esto, al menos, me parece que está bien dicho:
que los dioses son los que nos cuidan y que nosotros
los humanos somos una de sus posesiones"
PLATÓN, FEDÓN, 62b

Hoc pietate motum opusculum in matris memoriam dedicatur

El Eutifrón es un diálogo atractivo por diversas razones. La primera responde al carácter dramático de la conversación: sucesos y acciones donde se pone en juego la vida y la muerte. El pasado del adivino Eutifrón es violento y el futuro de Sócrates también lo será. $Y$ esos sucesos y acciones marcan la vida de los personajes en un terreno jurídico y, a la vez, religioso.

La segunda razón es de tipo moral. Platón es consciente del drama que teje porque enfoca ese ambiguo terreno de justicia y piedad. Esta curiosa mezcla nos embarca en una tragedia filosófica. Primero se recuerdan muertes del pasado (la de Sócrates también lo es para el autor) y luego se ilustra cómo desde esos hechos particulares arranca la reflexión. Arranca no para analizar las consecuencias de la conducta, sino para intentar decidir cuándo un comportamiento es justo o religiosamente aceptable. Como el culto y el derecho penal se derivan de acciones simbólicamente correctas o incorrectas, el simbolismo 
se concreta cuando la ley religiosa es también jurídicamente efectiva: de tipo punitivo y, por tanto, regulativo. La filosofía siempre tendrá en mente, a veces sin ahondar en esas leyes particulares, que saber distinguir cuándo una acción es síntoma de transgresión prevalece sobre la aplicación de la norma. Gracias a que la conducta simboliza algo condenable o elogiable es que corremos suertes opuestas ante la ley de los hombres y la de los dioses.

La tercera es de tipo histórico. La costumbre social de dicha aprobación y repudio se sedimenta en leyes religiosas orales; más adelante, el cuerpo escrito de leyes cívicas sigue reservando ciertas esferas jurídicas al influjo de las primeras. Si una acción es religiosamente condenable, entonces la sociedad tendrá que castigar al delincuente. Por ejemplo, como los asesinatos son peligrosos para la comunidad, la costumbre marca la mancha de sangre como síntoma de una contaminación religiosa: no sólo la acción es detestable, sino también el actor. Las leyes divinas señalan al transgresor con una mancha que lo excluye y condena; las leyes humanas se encargarán de ejecutar las consecuencias penales.

La cuarta es decididamente filosófica: aborda la relación entre lo divino y lo humano. Sucede que el simbolismo con el que trabaja el mito puede no tener ninguna validez jurídica en el presente. Notamos entonces que el culto cívico no siempre correrá parejo con el pasado mítico, que los dioses del culto vigilan la justicia humana, pero para ello también han de censurar sin arbitrariedad y aprobar con unanimidad. Es decir, para que el derecho religioso sea imparcial, los dioses han de valorar las acciones teniendo como norte un modelo de conducta. La acción simboliza algo correcto o incorrecto según tenga un rasgo que la aproxime o aleje de ese modelo, y no porque argumentemos simplemente que los dioses la aprueban o censuran. Más bien, su elogio y repudio están anclados en una sabia decisión en torno a las alternativas que plantea ese simbolismo. Surge entonces la necesidad de identificar un forma constante de la piedad independiente de la voluntad divina.

La quinta es de corte educativo. Las herramientas lógicas que buscan esclarecer en qué consiste la piedad parecen refutar todas las versiones que ofrece el profeta Eutifrón, experto en asuntos divinos. Sin embargo, el final del diálogo no tiene por qué abandonarnos a la duda. Un lector agudo encontrará las 
pistas para resolver el acertijo (cf. 13d-14b), pues la esencia de la piedad en el Eutifrón viene a ser la reinterpretación dialéctica del servicio socrático de la Apología. Vista en una nueva luz, la religión se revela como el arte subsidiario de un arte supremo: "¿Cuál es aquella excelente obra que los dioses producen utilizándonos a nosotros como servidores?" (I3e).

Según las pistas que se nos brindan, el culto religioso no tendrá que asumir ni a dioses antojadizos, ni tampoco a dioses que puedan ser aplacados en el ritual para así cambiar su veredicto. Más bien, la valoración divina distingue si la acción tiene ciertos rasgos que en toda ocasión son símbolos del camino que se propone trazar junto con los hombres. Cuando estos contribuyen a la construcción de ese camino podemos decir que son religiosos, que sirven a los dioses. Quizás esa obra de arte sea la realización de un orden moral; a ella apunta la exhortación socrática al cuidado del alma (la propia y la ajena), el mejor servicio para esos dioses que atienden al acontecer humano.

Esta reconfiguración de la relación hombre-dios no tiene precedentes en la religión griega: los dioses demasiado humanos de Homero y Hesíodo han devenido esencialmente morales, con una obra orientada a la perfección de las almas bajo su cuidado. En su misión filosófica, Sócrates se vio como un servidor que seguía las órdenes de un dios filantrópico. Aquí se nos aclara en qué sentido se lo acusó de inculcar una "novedad" religiosa en la Atenas liberal, pero decadente, de fines del siglo $\mathrm{V}$ a.C.

\section{Nota sobre la traducción}

La presente traducción está basada en el texto y las aún excelentes notas de la edición de John Burnet (Plato's Euthyphro, Apology of Socrates and Crito, Oxford: Oxford University Press, 1924). A mi entender, no carece de sentido colocar entre paréntesis los términos griegos claves: se causa menor daño al lector indocto que beneficio al docto.

Las notas que adjunto al pie de página tienen un sólo cometido: ilustrar nombres, alusiones o prácticas susceptibles de no ser comprendidas en una primera lectura. Si esa tarea demanda una extensión inquietante, ello se debe 
a la extrañeza del punto tratado y no a una pretensión de exhaustividad. En caso contrario, no habría obviado ciertas referencias a otros diálogos platónicos (sobre todo en relación con el pasaje 5e-6c, de abundantes paralelos con la República, 377e-378d) ni tomado la licencia de explayarme en el relato didáctico de un mito desconocido u olvidado por el lector. Tratar de resolver, por ejemplo, el enigma acerca del preciso estadio de desarrollo de la 'Teoría de las Ideas' (cf. 5c-d y 6d-e) hubiera implicado oscurecer lo que se quiere aclarar.

En aras de la honestidad de esa tarea, debo reconocer que mi deuda directa con Burnet y otros autores es tan frecuente que dejar constancia de ella habría vuelto a las notas más barrocas de lo que ya son. Muchas veces, cuando creía que una conexión mía podía ser inédita, he verificado a posteriori que figuraba en un autor pretérito, al que quizás le sucedía lo mismo respecto a su predecesor. El lector escrupuloso al que le perturbe este eclecticismo anónimo podrá repetir la misma experiencia consultando los títulos que destaco en la 'Bibliografía': descubrirá entonces cuán poco originales han sido mis notas, cuán poco pretenciosos mis esfuerzos.

Asimismo, he consultado la última edición crítica del texto griego (Platonis Opera. Tomus I, edición de E.A. Dukey otros, Oxford: Oxford University Press, 1995). Casi un siglo después, la vigencia de Burnet la ratifica el editor del Eutifrón (W.S.M. Nicoll) cuando comprobamos que sólo figuran dos innovaciones significativas (cf. 4bl y l4c4). Hay modestas razones para obedecerlas aquí.

Por último, vayan mis sinceros agradecimientos a Federico Camino, Carlos Gatti y José León Herrera -a quien debo, en especial, mi aprendizaje del griego-, sin cuyas sugerencias no hubiera sido posible esta versión final. Su paciencia y dedicación me han ayudado a superar problemas de diversa índole, así que espero retribuirles su tiempo con esta pequeña mención. Tampoco puedo olvidarme del afán con que Alberto Castillo leyó el trabajo, ni de sus felices acabados. 


\section{Bibliografía}

\section{Bibliografía de la traducción}

a) Léxicos y gramáticas

Goodwin, W.W., Syntax of the Moods and Tenses of the Greek Verb, Londres: Macmillan \& Co, 1889.

Liddell, H.G., R. Scotty H.S. Jones, A Greek-English Lexicon, Oxford: Clarendon Press, 1940.

Radice, Roberto, Lexicon I: Plato, Milán: Biblia, 2003.

Smith, William (ed.), A Dictionary of Greek and Roman Antiquities, 3ra. edición, Londres: John Murray, 1890.

- (ed.), A Dictionary of Greek and Roman Biography and Mythology, 3ra. edición, Londres: John Murray, 1890.

b) Ediciones y traducciones utilizadas en las notas

Kinkel, Gottfried, Epicorum Graecorum Fragmenta, Leipzig: Teubner, 1877. López Eire, Antonio, Ilíada, Madrid: Cátedra, 1989.

Nauk, August, Tragicorum Graecorum Fragmenta, 2da. edición, Leipzig: Teubner, 1889.

Pabón, José Manuel, Odisea, Madrid: Gredos, 1986.

- y Manuel Fernández Galiano, República, Madrid: Instituto de Estudios Políticos, 1969.

\section{Bibliografía sobre el Eutifrón}

a) Ediciones del Eutifrón

Adam, James, Platonis Euthyphro, introducción, texto y comentario, Cambridge: Cambridge University Press, 1890.

Burnet, John, Plato's Euthyphro, Apology of Socrates and Crito, texto, aparato crítico y comentario, Oxford: Oxford University Press, 1924.

Croiset, Maurice, Hippias Mineur, Alcibiade I, Apologie de Socrate, Euthyphron, Criton, introducciones, texto bilingüe griego-francés, aparato crítico y notas, París: Les Belles Lettres (Assoc. Guillaume Budé), 1920.

Duke, E.A., W.F. Hicken, W.S.M. Nicoll, D.B. Robinson y J.C.G. Strachan, Platonis Opera. Tomus I, texto y aparato crítico, Oxford: Oxford University Press, 1995. 
Fowler, R.H., Euthyphro, Apology of Socrates, Crito, Phaedo, Phaedrus, introducciones, texto bilingüe griego-inglés y notas, Cambridge, Mass.: Harvard University Press (Loeb Classical Library), 1914.

Heidel, W.A., Plato's Euthyphro, introducción, texto, comentario y bibliografía, Nueva York: American Book Company, 1902.

b) Notas filológicas sobre el Eutifrón

Burnet, John, “Vindiciae Platonicae”, en: The Classical Quarterly 8, No. 4 (1914), pp. 230-236.

- "Vindiciae Platonicae II", en: The Classical Quarterly 14, No. $3 / 4$ (1920), pp. 132-138.

Heidel, W.A., “Non-reciprocal Uses of $\dot{\alpha} \lambda \lambda \eta \dot{\lambda} \omega \omega v$ ”, en: Classical Philology 23, No. 2 (1928), pp. I76-179.

c) Traducciones castellanas del Eutifrón

Eutifrón. Apología. Critón, texto bilingüe griego-español, introducciones, traducción y notas por Juan David García Bacca, México D.F.: Universidad Nacional Autónoma de México, 1944.

Eutifrón, o de la piedad, prólogo, traducción y notas por José Antonio Miguez, Buenos Aires: Aguilar, 1963.

Diálogos I: Apología, Critón, Eutifrón, lón, Lisis, Cármides, Hipias Menor, Hipias Mayor, Laques, Protágoras, introducción, traducción y notas del Eutifrón por Julio Calonge Ruiz, Madrid: Gredos, 1981.

Eutifrón, traducción, análisis, notas y bibliografía por Alfonso Gómez-Lobo, Santiago: Editorial Universitaria, 1996.

d) Estudios sobre el Eutifrón

Allen, R.E., Plato's 'Euthyphro' and the Earlier Theory ofForms, Londres: Routledge \& Kegan Paul, 1970.

Benson, Hugh (ed.), Essays on the Philosophy of Socrates, Oxford: Oxford University Press, 1992.

Bloch, Herbert, "The Exegetes of Athens and the Prytaneion Decree", en: The American Journal of Philology, LXXIV, No. 4 (1953), pp. 407-4I8.

Brickenhouse, T.C.y N.D. Smith, “The Origin of Socrates' Mission”, en:Journal of the History of Ideas, XLIV (1983), pp. 657-666.

Burnyeat, M.F., "The Impiety of Socrates", en: Ancient Philosophy, XVII, No.I (1997), pp. I- 12 (reimpreso en: Kamtekar, Rachana (ed.), Plato's Euthyphro, Apology, and Crito, pp. 150-162). 
Cattanei, Elisabetta, "¿Es justo acusar de homicidio al propio padre por haber dejado morir a un dependiente? Reflexiones sobre los 'derechos humanos' en el pensamiento de Platón”, en: Areté, XV, No. I (2003), pp. 63-8I.

Cohen, S. Marc, 197I. "Socrates on the Definition of Piety: Euthyphro IOA-IIB", en:Journal of the History of Philosophy, IX, pp. I-I3 (reimpreso en: Kamtekar, Rachana (ed.), Plato's Euthyphro, Apology, and Crito, pp. 35-48).

Desjardins, Rosemary, Plato and the Good. Illuminating the Darkling Vision, Leiden/Boston: Brill, 2003, capítulos 5 y 6.

Edwards, M.J., “In Defense of Euthyphro", en: The American Journal of Philology, CXXI, No. 2 (2000), pp. 2I3-224.

Ferguson, A.S., "The Impiety of Socrates", en: The Classical Quarterly, VII, No. 3 (1913), pp. 157-175.

Fineberg, Stephen, “Plato's Euthyphro and the Myth of Proteus", en: Transactions of the American Philological Association, CXII (1982), pp. 65-70.

Furley, W.D., "The Figure of Euthyphro in Plato's Dialogue", en: Phronesis, XXX, No. 2 (1985), pp. 20I-209.

Geach, P.T. , “Plato's Euthyphro: An Analysis and Commentary", en: The Monist, L, No. 3 (1966), pp. 369-382 (reimpreso en: Kamtekar, Rachana (ed.), Plato's Euthyphro, Apology, and Crito, pp. 23-34).

Gómez-Lobo, Alfonso, "Sobre la ontología del Eutifrón”, en: Méthexis, X (1997), pp. 39-44.

Guthrie, W.K.C., A History of Greek Philosophy. Volume IV. Plato: The Man and His Dialogues, Earlier Period, Cambridge: Cambridge University Press, 1975, capítulo IV: "Early Socratic Dialogues", pp. I0I-124.

Heidel, W.A., "On Plato's Euthyphro", en: Transactions and Proceedings of the American Philological Association, XXXI (1900), pp. 163-181.

Higginson, T.W., "Philanthropy", en: Transactions of the American Philological Association, V (I874), pp. 20-22.

Hoerber, R.G., “Plato's Euthyphro”, en: Phronesis, III, No. 2 (1958), pp. 95107.

Hoopes, J.P., "Euthyphro's Case", en: The Classical Bulletin, XLVII, No. I (1970), pp. I-6.

Kahn, Charles, Plato and the Socratic Dialogue. The Philosophical Use of a Literary Form, Cambridge: Cambridge University Press, 1996, capítulo 6: "The Priority of Definition: from Laches to Meno", pp. 170-178.

- "Was Euthyphro the Author of the Derveni Papyrus?", en: Laks, A. y G.W. Most (eds.), Studies on the Derveni Papyrus, Oxford: Oxford University Press, 1997, pp. 55-63.

Kamtekar, Rachana (ed.), Plato's Euthyphro, Apology, and Crito, Maryland: Rowman \& Littlefield Publishers, 2005. 
Klonoski, R.J., "The Portico of the Archon Basileus: On the Significance of the Setting of Plato's Euthyphro", en: The Classical Journal, LXXXI, No. 2 (1986), pp. 130-137.

Lledó Íñigo, Emilio, “La estructura dialéctica del Eutifrón platónico”, en: Revista de Filosofía del Instituto Luis Vives, XVII, No. 67 (1958), pp. 363-393.

MacNaghten, R.E., "Socrates and the $\delta \alpha$ uóviov", en: The Classical Journal, XXVIII, No. 6 (1914), pp. 185-189.

McPherran, Mark L., "Socratic Piety in the Euthyphro", en:Journal of the History of Philosophy, XXIII (1985), pp. 283-309 (reimpreso en: Benson, Hugh (ed.), Essays on the Philosophy of Socrates, pp. 220-24I).

- “Justice and Pollution in the Euthyphro", en: Apeiron, XXXV (2002), pp. 105-127 (reimpreso en: Kamtekar, Rachana (ed.), Plato’s Euthyphro, Apology, and Crito, pp. I-22).

Ooms, Nicole, "Dédalo y Platón: el espacio escultórico del Eutifrón", en: Tópicos, XXXI (2006), pp. 147-163.

Panagiotou, Spiro, "Plato's Euthyphro and the Attic Code on Homicide", en: Hermes, CII, No. 3 (1974), pp. 419-437.

Rabinowitz, W.G., "Platonic Piety: An Essay Toward the Solution of an Enigma", en: Phronesis, III (1958), pp. 108-I20.

Rosen, Frederick, "Piety and Justice: Plato's Euthyphro", en: Philosophy, XLIII (1968), pp. 105-II6.

Strauss, Leo, The Rebirth of Classical Political Rationalism. Essays and Lectures by Leo Strauss, selección e introducción por Thomas Pangle, Chicago: University of Chicago Press, 1989, capítulo 8: “On the Euthyphron”, pp. 187-206.

Tate, J., "Socrates and the Myths", en: The Classical Quarterly, XXVII, No. 2 (1933), pp. 74-80.

- "Reply to Professor A.E. Taylor", en: The Classical Quarterly, XXVII, No. 3/4 (1933), pp. 159-161.

Taylor, A.E., Plato. The Man and His Work. Londres: Methuen \& Co., 1926, capítulo VII: "Socratic Dialogues: Euthyphro, Apology, Crito", pp. I46-I56.

- "Socrates and the Myths", en: The Classical Quarterly, XXVII, No. 3/4 (1933), pp. 158-159.

Taylor, C.C.W., "The End of the Euthyphro", en: Phronesis, XXVII, No. 2 (1982), pp. 109-1I8.

Vlastos, Gregory, Socrates: Ironist and Moral Philosopher, Nueva York: Cornell University Press, 1991, capítulo 6: “Socratic Piety”, pp. 157-178 (reimpreso en: Kamtekar, Rachana (ed.), Plato's Euthyphro, Apology, and Crito, pp. 49-7I).

Weston, A.H., "The Question of Plato's Euthyphro", en: The Classical Bulletin, XXVII, No. 5 (195I), pp. 57-58. 


\section{Eutifrón \\ [O sobre lo piadoso; un diálogo tentativo]}

\section{EUTIFRÓN, SÓCRATES}

2a EUTIFRÓN. ¿Qué novedad ha ocurrido, Sócrates, para que tú, abandonando tus estancias en el Liceo', ahora pases tu tiempo aquí, cerca del pórtico del arconte-rey²? Seguro que no tienes también un juicio ante el arconte-rey, tal como yo.

SÓCRATES. De hecho, Eutifrón, los atenienses no lo llaman un juicio sino una acusación pública ${ }^{3}$.

b EUTIFRÓN. ¿iQué dices!? ¿Alguien te ha denunciado, según parece, en una acusación pública? Pues no te voy a atribuir esto: que tú se lo hayas hecho a otro.

SÓCRATES. No, por cierto.

EUTIFRÓN. ¿Entonces otro a ti?

SÓCRATES. Sí.

EUTIFRÓN. ¿Quién?

SÓCRATES. Ni yo mismo conozco bien al sujeto, Eutifrón, pues me parece que es alguien joven y desconocido. Pero creo que lo llaman Meleto. Es del demo de Piteo, si recuerdas a algún Meleto Piteano de pelo lacio, barbilampiño y de nariz aguileña.

EUTIFRÓN. No lo recuerdo, Sócrates. Más bien, ¿en qué consiste la acusación con la que te ha denunciado?

SÓCRATES. ¿Cuál es? Nada despreciable, en mi opinión; pues haber comprendido tamaño asunto siendo tan joven no es pequeña cosa. Como dice, él sabe de qué manera los jóvenes son corrompidos y quiénes son los que los corrompen. Es posible que sea alguien sabio que, observando mi estupidez al corromper a los de su edad, ahora corre a acusarme ante la ciudad, tal como ante su madre. $Y$ me parece que es el único que

\footnotetext{
I Uno de los tres grandes gimnasios situados fuera de las murallas de Atenas - los otros dos eran la Academia y el Cinosarges. Estaba dedicado a Apolo Liceo y se ubicaba en el suburbio oriental, no lejos del río ílisos. No mucho tiempo después, Platón y Aristóteles habrían de fundar sus respectivas 'escuelas' -la Academia y el Liceo- en el terreno de los gimnasios homónimos.

2 El arconte-rey, designado anualmente por sorteo, era el segundo de los nueve arcontes y había heredado las funciones religiosas de los viejos reyes de Atenas. Todos los antiguos sacrificios patrios eran presididos por él. Su competencia jurídica se extendió, naturalmente, a todos los casos que involucraban la religión del Estado. Como Sócrates fue denunciado por impiedad, esto es, por una ofensa contra la religión patria, tiene que comparecer ante el arconte-rey para la instrucción preliminar. Cf. Platón, Político, 290e; Aristóteles, Constitución de los atenienses, 57.1-4.

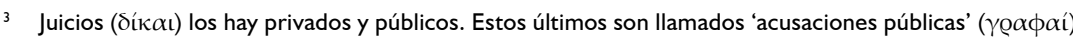
y en ellos no es el Estado ateniense el que denuncia, sino un ciudadano cualquiera -como Meleto- que asume la responsabilidad de hacerlo y solicita la pena para una falta cometida contra el Estado. El caso de Eutifrón es distinto del de Sócrates, pues se trata de un juicio en el que se inicia un proceso por homicidio -donde la víctima es un particular. Este delito, de carácter más bien privado que público, caía también bajo la jurisdicción del arconte-rey, pues el Estado tomaba conocimiento del homicidio en la medida en que éste creaba una contaminación religiosa que, de no ser purgada, afectaría a la comunidad entera.
} 
empieza correctamente su carrera política; porque la manera correcta consiste en cuidar primero a los jóvenes para que sean los mejores -tal como un buen campesino naturalmente cuida primero a las plantas más jóvenes y, recién luego, a las demás. Quizás también en este caso Meleto arranca primero la mala hierba -a nosotros, los corruptores de los jóvenes brotes, como dice-y después de ello es evidente que, tras cuidar a los más viejos, será responsable de grandísimos e innumerables bienes para la ciudad, como es natural que ocurra cuando parte de tal comienzo.

EUTIFRÓN. Quisiera que fuera así, Sócrates, pero me aterra que suceda lo contrario. Sencillamente, me parece que atenta contra la ciudad empezando por su corazón, al intentar cometer una injusticia contra ti. Pero dime, ¿qué dice que haces para corromper a los jóvenes?

b SÓCRATES. Cosas extrañas, mi admirable, a primera oída. Dice que soy un fabricante de dioses ( $\pi$ oıๆ $\tau \dot{\eta} v \theta \varepsilon \tilde{\omega} v$ ) y, por fabricar nuevos dioses y no rendir culto a los antiguos, me denunció en nombre de estos últimos, como dice.

EUTIFRÓN. Entiendo, Sócrates: es porque tú dices que la señal divina ${ }^{4}$ (†ò $\delta \alpha \mu$ uóvıov) te sobreviene de vez en cuando. Así, por innovador en relación con los asuntos divinos, te ha denunciado en esta acusación pública y se dirige al tribunal con la intención de calumniarte, sabiendo que ese tipo de cosas son fácilmente tergiversables ante la mayoría ${ }^{5}$. De hecho, también se burlan de mí como si fuera un loco cuando pronuncio algo en la Asamblea en relación con los asuntos divinos, prediciéndoles el porvenir. Aun

\footnotetext{
4 Una voz que disuadía a Sócrates de algo desafortunado que estaba a punto de hacer, pero que jamás lo incitaba a tomar un curso de acción. I) No se trata de la voz de la conciencia, pues se limitaba al futuro y no manifestaba esa aprobación o desaprobación que sigue a nuestros actos. 2) Tampoco se refiere a la conciencia moral, pues la "señal divina" se le aparecía en ocasiones incluso triviales para inhibir actos cuyas consecuencias serían desafortunadas -no para resolver dilemas serios acerca del bien y el mal. 3) Más aun, Sócrates habla abiertamente de ella como algo que le es familiar desde niño: no tenía, por tanto, nada que ver con la misión filosófica que el dios de Delfos le encomendaría más tarde (una misión que, en cambio, sí respondía a una orden positiva). 4) Sin embargo, la señal provenía de ese mismo dios, de ahí que la expresión

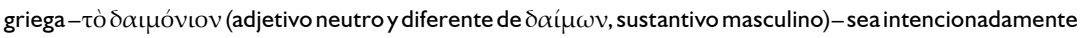
vaga e impersonal: indica un origen divino, pero no es ninguna divinidad de ningún tipo. 5) No es, por tanto, un dios o semidiós personal, externo o interno, 'el dios de Sócrates', sino una señal que Sócrates acoge, una voz que escucha. Cf. Platón, Apología, 3lc-d, 40a-c, 4ld; Jenofonte, Apología, 12-13, Memorabilia, I.I.2-9.

5 Eutifrón inmediatamente asume que la acusación de innovación religiosa tiene a la "señal divina" como fundamento (cf. Platón, Apología, 3Id; Jenofonte, Memorabilia, I.I.2). Según él, la señal se presta a la malinterpretación, pudiendo ser tergiversada ante los jueces como si se tratara de una divinidad nueva, creación exclusiva de Sócrates. De hecho, como éste afirmaba que la señal era una experiencia única, sin precedentes en ninguna otra persona (cf. Platón, República, 496c), los atenienses podrían envidiar que tuviese un acceso privilegiado a un canal divino del que ellos se vieren privados (cf. Jenofonte, Apología, 14). Por lo visto, Eutifrón considera a Sócrates como un espíritu afín, que también se sirve de la 'adivinación' (otro apelativo que se le da a su señal en la Apología platónica, 40a) y que sufre por igual las consecuencias de los prejuicios populares (cf. ibid, 18d, 28a). No es, pues, un partidario del fanatismo que fue responsable de la muerte de Sócrates; al contrario, no se ha enterado de su juicio y, cuando se entera, le da palabras de aliento y condena a su acusador.
} 
cuando no haya nada falso en las cosas que haya predicho, igual nos envidian a todos los que somos así. Pero por nada hay que preocuparse de ellos, sino salirles al encuentro. SÓCRATES. Mi estimado Eutifrón, ser objeto de burlas quizás no importa. Pues, según creo, los atenienses no se interesan tanto cuando consideran a alguien un experto -a no ser que se dedique a impartir su propia sabiduría-. Pero con quien consideran que vuelve semejantes a los demás, sí se molestan: ya sea a través de la envidia, como tú dices, o por algún otro medio.

EUTIFRÓN. No estoy particularmente deseoso de probar cómo se portan conmigo en relación con esto.

SÓCRATES. A lo mejor tú das la impresión de que te muestras reservado y ni se te

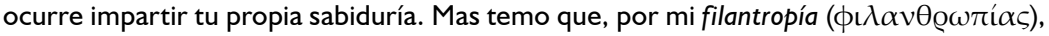
yo les dé la impresión de que declaro profusamente a cualquier hombre lo que sea que tengo, no sólo sin paga, sino añadiéndola con gusto si alguien se digna escucharme. En todo caso, si, como decía justo ahora, se fueran a burlar de mí, como tú dices que de ti, no sería nada desagradable pasar el tiempo en el tribunal riéndonos y jugando; pero si se ponen serios, entonces será incierto cómo resultará la cosa, excepto para ustedes los adivinos.

EUTIFRÓN. Tal vez no va a haber ningún problema, Sócrates, sino que tú enfrentarás tu juicio satisfactoriamente y me imagino que yo también el mío.

SÓCRATES. Y bien, ¿qué hay de tu juicio, Eutifrón? ¿Te defiendes o demandas a alguien?

EUTIFRÓN. Demando.

SÓCRATES. ¿A quién?

4a EUTIFRÓN. Por perseguir a quien persigo, de nuevo parezco loco.

SÓCRATES. ¿Por qué? ¿Acaso persigues a alguien con alas?

EUTIFRÓN. Está lejos de volar, pues resulta ser muy anciano.

SÓCRATES. ¿Quién es?

EUTIFRÓN. Mi padre.

SÓCRATES. ¿iTu padre, amigo!?

EUTIFRÓN. En efecto.

SÓCRATES. ¿Cuál es el cargo y sobre qué gira el juicio?

EUTIFRÓN. Homicidio, Sócrates.

SÓCRATES. iPor Heracles! Es un hecho, Eutifrón, que la mayoría desconoce dónde

yace lo correcto. No creo que cualquiera haría correctamente lo que tú haces, sino alguien ya adelantado en el camino de la sabiduría.

EUTIFRÓN. Por Zeus, muy adelantado, Sócrates.

SÓCRATES. ¿Era alguno de tus familiares el asesinado por tu padre? ¿No es acaso evidente? Pues en nombre de un extraño no lo procesarías por homicidio... 
EUTIFRÓN. Me da risa, Sócrates, que pienses que en algo se diferencia si el asesinado era un extraño o un familiar ${ }^{6}$, y que no consideres, por el contrario, que sólo hay que vigilar si es que el homicida lo asesinó con justicia o no ${ }^{7} .$. y si lo hizo con justicia, dejarlo ir; si no, procesarlo, si precisamente el homicida vive contigo bajo el mismo techo y es tu comensal. Pues surge la misma contaminación ( $\mu$ í $\alpha \sigma \mu \alpha)$ en caso de que convivas con él como confidente y no te purifiques ni a ti mismo ni a él procesándolo ante la justicia. A pesar de que, en este caso, el muerto era un jornalero mío que, cuando cultivábamos nuestras tierras en Naxos, trabajaba para nosotros allí. Ahora bien, en medio de su borrachera, se enfureció con uno de nuestros esclavos domésticos y lo degolló. Luego mi padre, tras atarlo de pies y manos y arrojarlo a una fosa, envía aquí a un hombre para preguntar al exégeta ${ }^{8}$ lo que era necesario hacer. En ese lapso, se mostraba negligente y descuidaba al hombre encadenado por ser éste asesino y como que no importaba si también moría. Lo que justo le pasó: debido al hambre, al frío y a las cadenas, murió antes de que llegara el mensajero de donde el exégeta. Por eso se molestan mi padre y el resto de mis familiares, porque yo, en nombre de ese homicida, proceso a mi padre por homicidio; que ni siquiera lo asesinó, como dicen ellos, y si lo mató, nunca tanto, ya que el muerto era un homicida y, por tanto, no hay que preocuparse por esa persona: pues es impío que un hijo procese a su padre por homicidio. Saben muy mal, Sócrates, cuál es la actitud de lo divino (tò $\theta \varepsilon i ̃ o v)$ respecto de lo piadoso y lo impío.

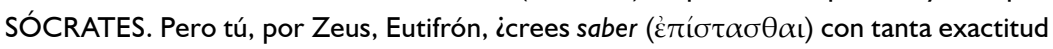
lo relativo a los asuntos divinos -cómo se comportan-y a las cosas piadosas e impías, que, sucedidos los hechos tal como tú los cuentas, no temes realizar, a tu vez, una acción impía al enjuiciar a tu padre?

EUTIFRÓN. Sería un bueno para nada, Sócrates, y ni siquiera Eutifrón podría distinguirse en algo de la mayoría de los hombres, si no supiera con exactitud todas estas cosas.

\footnotetext{
6 Según la ley ateniense, el derecho de procesar a un tercero por homicidio era obligatorio sólo para los familiares de la víctima o, en el caso de un esclavo, para su amo. Pero aquí el muerto es un jornalero de Eutifrón -ni familiar ni esclavo suyo. Al parecer, Eutifrón sostiene que la diferencia recordada por Sócrates no tiene mayor importancia, así que prefiere preguntarse si la muerte fue ocasionada con derecho de asesinato o no. Como él considera que no, la convivencia con el victimario lo vuelve confidente de un crimen cuya contaminación religiosa atestigua la desaprobación divina. Procesar a su padre es el camino que ve para purificarse junto con él y la diferencia mentada no puede significarle un obstáculo.

7 Cf. Platón, Apología, 28b: "Sólo hay que examinar, cuando actúe, si es que realiza acciones justas o injustas".

8 Esta es la primera mención en la literatura griega conservada del cargo de exégeta. Los exégetas de Atenas eran los expositores del ancestral derecho sagrado y, según Platón (Leyes, 759d), eran sólo tres. Provenían de las antiguas familias nobles y debían interpretar las leyes religiosas no-escritas relativas a asuntos ceremoniales, funerarios y expiatorios. Por lo demás, no tenían nada que ver con la interpretación de oráculos. El exégeta al que consulta el padre de Eutifrón estaba encargado de orientar a los que se veían envueltos en alguna contaminación religiosa (derivada, en este caso, del homicidio cometido por el jornalero). Los procedimientos-judiciales o rituales-sugeridos por él le permitían al consultante obediente liberarse de la misma.
} 
SÓCRATES. ¿Acaso no es lo mejor para mí, mi admirable Eutifrón, volverme alumno tuyo y, antes del juicio público contra Meleto, desafiarlo en este mismísimo punto (diciéndole que yo, aun en el pasado, valoraba mucho saber los asuntos divinos y que ahora, puesto que él dice que cometo una falta al hablar temerariamente y presentar innovaciones en relación con los asuntos divinos, me he vuelto alumno tuyo... “Meleto”, le diría entonces, "si admites que Eutifrón es sabio en tales cuestiones, considera que yo también rindo culto correctamente y retira tu acusación; pero si no, llévalo a juicio a él, al maestro, antes que a mí, por corromper a los más viejos, a mí y a su propio padre: por instruirme a mí y por amonestarlo a éste y castigarlo") y, en caso de que no se deje convencer ni me libere del juicio ni te denuncie a ti en lugar de a mí, decir estas mismas cosas en el tribunal, aquellas con las que lo desafié?

EUTIFRÓN. Por Zeus, Sócrates, que si intentara denunciarme encontraría, según creo, su punto débil, y se nos armaría en el tribunal una discusión en torno a él mucho antes que en torno a mí.

SÓCRATES. Y yo, dándome cuenta de esto, mi querido amigo, siento ganas de volverme tu alumno, sabiendo que ese tal Meleto -y, sin duda, cualquier otro- sencillamente finge no verte, mientras que tan aguda y fácilmente puso el ojo sobre mí, que me denunció por impiedad. Ahora bien, dime, por Zeus, lo que hace un rato asegurabas saber claramente... ¿De qué clase dices que es lo piadoso y lo impío, no sólo acerca del homicidio sino también respecto a las demás cosas? ¿No es lo piadoso igual a sí mismo en toda acción, mientras que, a su vez, lo impío es lo contrario de todo lo piadoso, pero idéntico a sí

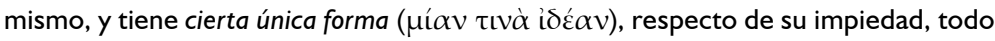
aquello que resulte ser impío?

EUTIFRÓN. Totalmente, Sócrates.

SÓCRATES. Dime, pues, ¿qué afirmas que es lo piadoso y qué lo impío?

EUTIFRÓN. Bueno, yo digo que lo piadoso es lo que ahora llevo a cabo: procesar al que delinque cometiendo una falta en relación con el homicidio, el robo de propiedades consagradas o cualquier otra cosa de este tipo, -aun cuando resulte ser tu padre, tu madre o cualquier otra persona-; y que lo impío es no procesarlo. Porque mira, Sócrates, qué

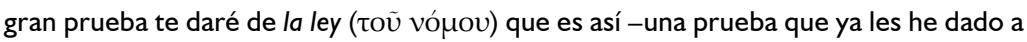
otros de que sería correcto que las cosas sucedieran de este modo-: no ceder ante quien cometa una impiedad, sin importar de quién se trate ${ }^{10}$. Pues da la casualidad de que los

\footnotetext{
9 Según diversos intérpretes, ya en este pasaje aparece ilustrada la 'Teoría de las Ideas'. Nótese que Sócrates exige una única forma de lo piadoso I) que sea la misma en todas las acciones que han de llamarse 'piadosas', 2) que comporte una auto-identidad estricta -esto es, una acción piadosa no puede ser impía a la vez, dado que tiene una única forma que es sólo igual a sí misma en tanto 3) que asume su contrariedad intrínseca respecto de la forma de lo impío (a la que, a su vez, se le aplican los mismos criterios, aunque con los adjetivos invertidos). Para la dialéctica platónica es fundamental la mutua implicancia de todos estos 'criterios'. Véase, más adelante, 6d-e.

10 Según Eutifrón, esta ley derivada de la conducta de los dioses no se trata de la ley meramente humana de Atenas, sino de una ley divina no-escrita, revelada gracias a su sabiduría religiosa. Como tal, Eutifrón
} 
mismos seres humanos rinden culto a Zeus como el mejor y el más justo de los dioses, y admiten que él encadenó a su propio padre porque se tragó a sus hijos de manera injusta, y que éste, a su vez, castró a su propio padre por razones similares". Sin embargo, se irritan conmigo porque proceso a mi padre cuando delinque $y$, de esta manera, ellos mismos se contradicen en lo que afirman en cuanto a los dioses y en cuanto a mí. SÓCRATES. ¿No será por esto, Eutifrón, que me veo envuelto en una acusación pública, porque cuando alguien cuenta tales cosas acerca de los dioses las acepto con fastidio ${ }^{12}$ ? A causa de esto, seguro cualquiera dirá que cometo una falta. Ahora, si a ti -el que sabe tanto sobre tales cosas- te parecen bien, es necesario, según creo, que también nosotros seamos de igual parecer. ¿Pues qué vamos a decir nosotros, los mismos que confesamos no saber nada de ellas? Pero dime, por Zeus, el dios de la amistad, ¿tú en verdad crees que estas cosas han sucedido así? EUTIFRÓN. Y todavía otras más sorprendentes que éstas, Sócrates, que la mayoría desconoce.

SÓCRATES. ¿También consideras tú que, en realidad, hubo guerra entre los dioses, los unos contra otros, $y$ enemistades terribles y batallas ${ }^{13}$ y muchas otras cosas por el estilo,

sólo puede apelar a los indicios que de ella ofrece la mitología. Si bien sus opositores admiten los hechos míticos citados a continuación, no pueden aceptar que de ellos se siga que la moralidad de los dioses ha de modelar la de los hombres. Al asumir esta inusual inferencia, Eutifrón se cree plenamente justificado cuando le imputa inconsistencia a sus críticos y procesa a su padre por cometer, como Cronos y Urano, una injusticia e impiedad.

"La singular historia figura en la Teogonía de Hesíodo. Urano, el cielo, oculta con malicia a sus hijos habidos con su madre Gea, la tierra, en el seno de Gea. El menor de ellos, Cronos, convencido por su madre, siega con una hoz los genitales de su padre y se torna rey de los inmortales (versos 154-210). Luego Cronos se entera por sus padres de que estaba destinado a ser destronado por uno de sus hijos habidos con su hermana Rea, de modo que se los traga conforme van siendo paridos. Pero al estar encinta de Zeus, Rea, bajo consejo de sus padres, da a luz a su último hijo en la isla de Creta, lejos de la vigilancia de Cronos, a quien le entrega una piedra envuelta en un pañal para que se la trague en lugar del recién nacido. Una vez que crece inadvertido, Zeus se vale de un engaño de Gea y logra que su padre Cronos vomite uno a uno a sus hijos, incluida la piedra (versos 453-506).

El episodio de violencia familiar concluye cuando Gea, la intrigante abuela de Zeus, insta a sus nietos Olímpicos a luchar, junto con los Centímanos, en contra de Cronos y sus hermanos -los Titanes. Al final, los dioses de la tercera generación resultan vencedores tras una batalla cósmica conocida como la Titanomaquia. Zeus, armado de rayo y trueno, consigue encadenar a su padre y a los otros Titanes en el Tártaro, en una prisión del subsuelo (versos 617-819).

12 Esta reserva de Sócrates puede considerarse el punto de partida de la crítica de Platón en la República a la 'teología' de los poetas. Curiosamente, allí se advierte el peligro educativo de las historias de la Teogonía, en clara referencia a la acción judicial de Eutifrón (378b): "No deben ser narradas en nuestra ciudad, ni se debe dar a entender a un joven oyente que, si comete los peores crímenes [sc. como Urano y Cronos] o castiga por cualquier camino la injusticia de su padre [sc. como Cronos y Zeus], no hará con ello nada extraordinario, sino solamente aquello de que han dado ejemplo los primeros y más grandes de los dioses".

13 Además de la Titanomaquia anteriormente citada, otro ejemplo paradigmático es la Teomaquia que relata Homero en la llíada (XX.I-74 y XXI.330-520). En plena guerra de Troya, se desencadena una batalla intestina entre los Olímpicos: los dioses partidarios de los aqueos luchan contra los dioses defensores del bando troyano en sendos combates singulares donde resultan victoriosos los dioses que apoyan a los griegos. 
cuales son contadas por los poetas y con las que, además, nuestros templos han sido adornados por los buenos pintores $y$, sobre todo, el peplo repleto de tales variopintos diseños que es conducido a la acrópolis en las Grandes Panateneas ${ }^{14}$ ? ¿Diremos que esas cosas son verdaderas, Eutifrón?

EUTIFRÓN. No solamente ésas, Sócrates, sino que, como te acabo de decir, yo te contaré con lujo de detalles, si efectivamente lo quieres, muchas otras cosas relativas a los asuntos divinos. Estoy seguro de que te quedarás con la boca abierta escuchándolas.

SÓCRATES. No me sorprendería; pero para otra oportunidad me las expondrás, en tu tiempo libre. Ahora, en cambio, intenta expresar con mayor claridad lo que hace un rato te pregunté. De hecho, amigo, la vez anterior no me instruiste suficientemente cuando te pregunté qué es lo piadoso, sino que me dijiste que justo esto resulta ser piadoso: lo que tú haces ahora al procesar a tu padre por homicidio.

EUTIFRÓN. Y decía cosas verdaderas, Sócrates.

SÓCRATES. Quizás; pero también afirmas, Eutifrón, que muchas otras cosas son piadosas.

EUTIFRÓN. También lo son.

SÓCRATES. ¿Recuerdas que no te exhortaba a que me enseñaras uno o dos de los

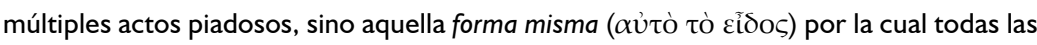
cosas piadosas son piadosas? Pues afirmaste que por una única forma ( $\mu \mathrm{i} \tilde{\alpha}$ i $\delta \varepsilon \dot{c}_{1}$ ) las cosas impías son impías y las piadosas, piadosas. ¿O acaso no te acuerdas?

EUTIFRÓN. Claro que sí.

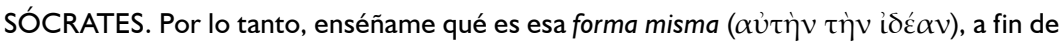

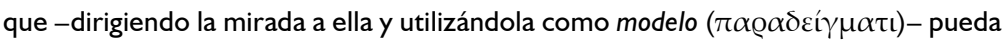
afirmar que aquel acto que tú u otro realicen, y sea tal como ella, es piadoso, y pueda negarlo de aquel que no sea tall'.

14 La festividad religiosa de las Panateneas se celebraba anualmente en Atenas a fines del primer mes del calendario (a inicios de nuestro agosto) y estaba consagrada a la diosa patria y al legendario rey Erecteo (cf. Homero, Ilíada, II.547-5I). Constaba de sacrificios cuantiosos y de una solemne procesión hasta el altar de Atenea en la acrópolis. Sin embargo, cada cuatro años se festejaban con inusuales pompas las Grandes Panateneas, en calidad de un certamen panhelénico. Estas incluían además la recitación de los poemas homéricos y concursos atléticos, ecuestres y musicales. El acto festivo más importante consistía en la presentación del nuevo peplo para la antigua estatua de Atenea Polias, peplo que las doncellas atenienses bordaban con meses de anticipación y que representaba la batalla de los dioses Olímpicos contra los Gigantes -particularmente, la victoria de Atenea sobre el gigante Encélado.

15 En este pasaje figuran otras tres aclaraciones importantes. I) Las múltiples acciones piadosas o impías tienen una única forma gracias a la cual son piadosas o impías, respectivamente. 2) Esta forma única puede ser utilizada por el agente moral como un modelo para distinguir en la práctica qué acciones son piadosas y cuáles no, pues discernir el modelo lo ayudará a reconocer sus instancias (acciones, personas). 3) Esto es posible gracias a que los actos piadosos o impíos guardan una correspondencia con su respectiva forma, correspondencia distinguible cuando uno dirige la mirada (sc. de la mente) a esa forma.

Por otro lado, se aclara que cuando Sócrates pregunta “iqué es lo piadoso?”, en realidad está preguntando por la forma misma (sc. como tal), así que la respuesta ha de dejar de lado sus atributos no-esenciales para lograr una definición correcta. Véase, más adelante, Ila. 
EUTIFRÓN. Si así lo quieres, Sócrates, te lo formularé de esa manera.

SÓCRATES. Por supuesto que lo quiero.

EUTIFRÓN. Pues entonces es piadoso lo que es agradable a los dioses e impío lo que no

$7 a$ les es agradable.

SÓCRATES. Excelente, Eutifrón: tal como yo buscaba que respondieras, así respondiste ahora. Si, en efecto, es verdadero, aún no lo sé, pero es evidente que tú me explicarás a continuación que es verdad lo que dices.

EUTIFRÓN. Ciertamente.

SÓCRATES. Vamos, examinemos qué estamos diciendo. Lo agradable a los dioses (Tò

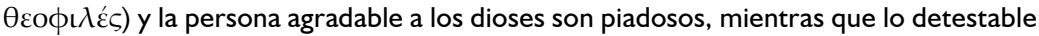
a los dioses y la persona detestable a los dioses son impíos. No son lo mismo, sino que lo piadoso es totalmente contrario a lo impío, ¿no es así?

EUTIFRÓN. Pues sí.

SÓCRATES. ¿Y te parece que ha sido bien expresado?

EUTIFRÓN. Así lo creo, Sócrates.

SÓCRATES. ¿No ha sido dicho también que los dioses forman facciones, Eutifrón, y están en desacuerdo mutuo y que hay mutua enemistad entre ellos?

EUTIFRÓN. Ha sido dicho.

SÓCRATES. ¿Sobre qué asuntos, amigo, trata la discordia, de modo que trae enemistad y cóleras? Examinémoslo de esta forma. Si tú y yo fuéramos a entrar en un desacuerdo relativo al número -por ejemplo, de dos conjuntos, cuál es más numeroso-, iacaso el desacuerdo sobre esto nos volvería enemigos y lograría encolerizarnos mutuamente, o, recurriendo al cálculo, nos reconciliaríamos rápidamente sobre tales cuestiones?

c EUTIFRÓN. Es cierto.

SÓCRATES. Luego, también, si entráramos en desacuerdo respecto a lo más grande y lo más pequeño, iacaso no cesaríamos rápidamente la discordia recurriendo a la medición? EUTIFRÓN. Así es.

SÓCRATES. ¿Y recurriendo al peso, según creo, lograríamos decidir lo relativo a lo más pesado y lo más ligero?

EUTIFRÓN. ¿Cómo no?

SÓCRATES. ¿Tras discrepar acerca de qué y al no poder recurrir a qué decisión, nos molestaríamos el uno contra el otro y nos volveríamos enemigos? Quizás para ti la respuesta no esté a la mano. Pero examina mientras yo hable si no es acaso acerca de lo justo y lo injusto, lo bello y lo feo, lo bueno y lo malo. ¿No es precisamente acerca de estas cosas que, envueltos en una discordia y no pudiendo recurrir a su decisión

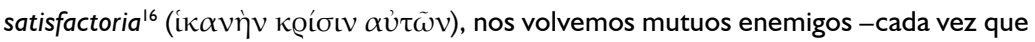

16 Para saber qué tipo de discordia desemboca en enemistades, se pregunta: I) cuáles son los temas sobre los que trata y 2) cuál es la situación que se tiene que cumplir. Cuando surge una discordia sobre el número, el tamaño o el peso, podemos recurrir a instancias de decisión efectivas (el cálculo, la medición, la balanza), pues nos permiten dirimir cuál de las dos partes tiene la razón. En cambio, la enemistad queda asegurada 
sucede-, no sólo tú y yo sino el resto de los hombres todos?

EUTIFRÓN. Esta es la discordia, Sócrates, y sobre estos temas.

SÓCRATES. ¿Y en cuanto a los dioses, Eutifrón? Si efectivamente entran en desacuerdo, ¿no discreparían por estas mismas razones?

EUTIFRÓN. Necesariamente.

e SÓCRATES. Entonces, según tu argumento, noble Eutifrón, de entre los dioses un grupo considera unas cosas justas $y$ otro otras, $y$ también bellas $y$ feas $y$ buenas $y$ malas. Pues no formarían facciones entre sí si no discreparan sobre estos asuntos, ¿o sí?

EUTIFRÓN. Hablas correctamente.

SÓCRATES. ¿Acaso cada grupo no ama las cosas que considera bellas, buenas y justas, mientras que detesta las contrarias a éstas?

EUTIFRÓN. Por cierto.

SÓCRATES. A las mismas cosas, como tú dices, unos las consideran justas, otros

8a injustas, y disputando en relación con ellas forman facciones y guerrean entre sí. ¿No es así?

EUTIFRÓN. Claro.

SÓCRATES. Luego, según parece, las mismas cosas son detestadas y amadas por los dioses, y resultaría que las mismas cosas son detestables y agradables a los dioses.

EUTIFRÓN. Así parece.

SÓCRATES. Y, por tanto, las mismas cosas serían piadosas e impías, Eutifrón, según este argumento.

EUTIFRÓN. Es probable.

SÓCRATES. Por lo visto, no respondiste lo que te pregunté, mi admirable; pues no te preguntaba por esto: aquello que, siendo lo mismo, resulta ser piadoso e impío a la vez. $Y$ así, aquello que sea agradable a los dioses también les sería detestable, según parece. De esta manera, Eutifrón, no sería nada sorprendente que, al emprender lo que tú haces ahora castigando a tu padre, realices algo agradable a Zeus, pero odioso para Cronos y Urano, y también agradable a Hefesto, pero odioso para Hera ${ }^{17}$, y del mismo modo en relación con

cuando surge una discrepancia respecto a si un acto es justo o injusto $y$, además, no podemos recurrir a una instancia que decida satisfactoriamente su valor.

Esto no implica que las cuestiones de hecho admiten siempre un procedimiento de decisión, pero que las cuestiones morales nunca. Por el contrario, a lo largo del diálogo se solicita una forma de lo piadoso que, al servir de modelo ( $c f .6 e$ ), nos permitirá decidir el valor de una acción controversial como la de Eutifrón. Así como existen conocimientos que nos permiten dirimir disputas en relación con el número, el tamaño o el peso, también habría un conocimiento de los contrarios morales que nos permitirá resolver las discordias en torno a ellos.

17 Véanse las palabras de Hefesto en la llíada (XVIII.394-7): "Cierto es que dentro de mi casa tengo yo una diosa [sc. Tetis] como huésped, venerable y digna de respeto, que me salvó cuando a mí me alcanzó el dolor que sentí al caer lejos por causa del deseo de mi madre, la de cara de perro, que me quiso ocultar por ser cojo". Lleno de rencor, el dios fabricó un trono de oro provisto de cadenas invisibles y se lo envió como regalo a su madre, la cual se vio encadenada al instante cuando se sentó sobre él. Los dioses solicitaron su liberación, pero Hefesto no tenía ganas de hacerle caso a ninguno, así que Dioniso -aquel con el cual tenía la 
los demás dioses, si algún otro discrepa de otro respecto al tema en cuestión. EUTIFRÓN. Pero yo creo, Sócrates, que ninguno de los dioses discrepa de otro en nombre de esto: que no ha de pagar la pena quien asesine a alguien de manera injusta. SÓCRATES. ¿Por qué? ¿Alguna vez escuchaste, Eutifrón, a algún humano disputando para lograr que el que asesina injustamente o realiza cualquier otra cosa de manera injusta no tenga que pagar la pena?

EUTIFRÓN. Sí, nunca terminan de disputar sobre estos asuntos, tanto en otras partes como en los tribunales. Pues cometen muchísimas injusticias, y alegan y hacen todo lo que pueden para evitar la pena.

SÓCRATES. ¿Acaso también reconocen, Eutifrón, que han cometido injusticia y, cuando lo reconocen, sin embargo alegan que ellos no han de pagar la pena?

EUTIFRÓN. De ninguna manera.

SÓCRATES. Entonces no alegan y hacen todo lo que pueden. Pues creo que no se atreven a alegar ni disputar en nombre de esto: que si precisamente cometen injusticia no han de pagar la pena; más bien, creo que alegan que no han cometido injusticia, io no? EUTIFRÓN. Eso es verdad.

SÓCRATES. Luego, no disputan sobre ello -que el que comete injusticia no ha de pagar la pena- sino quizás sobre esto: quién es el que comete injusticia, y haciendo qué y cuándo.

EUTIFRÓN. Es verdad lo que dices.

SÓCRATES. ¿Acaso no les sucede lo mismo a los dioses -si, según tu argumento, tienen rivalidades sobre las cosas justas e injustas-: cada facción alega que la otra ha cometido injusticia, mientras que la otra lo niega? No obstante, es claro que ninguno, mi admirable, ni de entre los dioses ni de entre los hombres, se atreve a alegar esto: que no ha de pagar la pena el que comete injusticia.

EUTIFRÓN. Sí, eso es verdad, Sócrates, en buena cuenta.

SÓCRATES. Bien, yo creo, Eutifrón, que los que disputan lo hacen en torno a cada acto en particular, se trate de hombres o dioses -si, en efecto, los dioses disputan. Es en relación a un acto en particular que entran en desacuerdo, $y$ unos alegan que éste ha sido realizado justamente, y los otros que de manera injusta. ¿No es así?

EUTIFRÓN. Por cierto.

SÓCRATES. Ven ahora, querido Eutifrón, enséñame también a mí, para que me vuelva más sabio... ¿Qué prueba tienes de que todos los dioses consideran, en primer lugar, que aquél murió de manera injusta -la persona que, mientras trabajaba a sueldo, resultó un asesino y, encadenado por el amo del muerto, terminó muriendo a causa de las cadenas antes de que el que lo encadenó averiguara de parte de los exégetas qué era necesario hacer con él-; $y$, en segundo lugar, que es correcto que el hijo, en nombre de esa persona,

mayor confianza-, tras emborracharlo y montarlo sobre un burro, lo restituyó al Olimpo y lo reconcilió con su madre. A este pintoresco mito alude Platón en la República (378d) cuando censura el "encadenamiento de Hera por su hijo". 
denuncie y procese al padre por homicidio? Ven, intenta mostrarme algo claro referente a esto: que, sin duda, todos los dioses consideran que esa acción es correcta. $Y$ en el caso de que me lo muestres con suficiencia jamás cesaré de alabarte por tu sabiduría. EUTIFRÓN. Quizás no es pequeña tarea, Sócrates, aunque te lo podría probar con bastante claridad.

SÓCRATES. Entiendo: es porque te parezco más estúpido que los jueces; puesto que es evidente que a ellos les probarás que lo sucedido es injusto y que todos los dioses detestan tales cosas.

EUTIFRÓN. Muy claramente, Sócrates, en caso de que me escuchen mientras hable.

SÓCRATES. Claro que te escucharán, en caso de que parezcas hablar bien. Pero mientras tú hablabas yo pensaba esto y reflexionaba conmigo mismo: "Si Eutifrón me enseñara, lo máximo posible, que todos los dioses consideran que tal muerte es injusta, ¿qué más habré aprendido de parte de Eutifrón sobre qué es lo piadoso y lo impío? Pues, según parece, ese suceso sería detestable a los dioses. Sin embargo, hace poco no aparecieron delimitados ( $\omega \varrho \iota \sigma \mu \varepsilon ́ v \alpha)$ por esto lo piadoso y su contrario. De hecho, lo que es detestable a los dioses también resultó que les era agradable”. Así que te dejo libre de probar eso, Eutifrón: si quieres, que todos los dioses $10^{18}$ consideren injusto y que todos lo detesten. Y bien, la enmienda que ahora estamos proponiendo en el argumento-que lo que todos los dioses detesten es impío; que lo que todos amen, piadoso; mientras que lo que unos amen y otros detesten no es ninguno de los dos o, si no, ambos a la vez-... ¿Quieres que

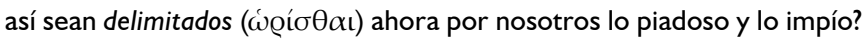

EUTIFRÓN. ¿Qué nos lo impide, Sócrates?

SÓCRATES. A mí nada, Eutifrón; más bien, examina tu posición: si, asumiendo

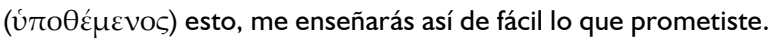
EUTIFRÓN. En efecto, yo diría que lo que todos los dioses amen es piadoso; mientras que lo contrario, lo que todos los dioses detesten, impío.

SÓCRATES. Y bien, ¿examinaremos nuevamente si esto, Eutifrón, ha sido bien expresado, o lo dejaremos pasar y aceptaremos sin más nuestra propuesta o la ajena, concediendo que la cosa es así si tan sólo alguien dice que lo es? ¿O hay que examinar qué quiere dar a entender el que habla? EUTIFRÓN. Hay que examinarlo; aunque, de hecho, yo creo que esto está ahora bien expresado.

18 Sc. "ese suceso", la muerte del jornalero. Recuérdese que más arriba (9a-b) Sócrates exige de Eutifrón dos pruebas claramente diferenciadas. La primera concierne al presunto carácter injusto de la muerte del jornalero bajo las circunstancias detalladas. La segunda está referida a la presunta rectitud de la acción de Eutifrón al procesar a su padre en nombre de un jornalero asesino -que no es ni familiar ni esclavo suyo. Aun cuando Sócrates le conceda a Eutifrón que todos los dioses consideran esa muerte como injusta, detestable y, por tanto, impía, de ello no se sigue que la segunda prueba quedaría ipso facto demostrada. Faltaría probar por qué no es impío procesar al padre por un homicidio comprobado como injusto e impío: esto es, por qué no atenta contra la sagrada piedad filial, virtud conservadora de toda familia griega (cf. 4a-b, e; Platón, Critón, 5la-c y República, 378b). 
10a SÓCRATES. Pronto lo sabremos mejor, amigo. Más bien, considera lo siguiente: ¿acaso lo piadoso es amado por los dioses porque es piadoso, o es piadoso porque es amado por los dioses?

EUTIFRÓN. No comprendo lo que dices, Sócrates.

SÓCRATES. Bueno, trataré de explicártelo de manera más clara. Nosotros decimos que hay algo transportado y algo que transporta, que hay algo conducido y algo que conduce, que hay algo visto y algo que ve, y por supuesto que entiendes que todas estas cosas son diferentes las unas de las otras y en qué difieren, ¿o no?

EUTIFRÓN. Creo que entiendo.

SÓCRATES. ¿Y también que hay algo amado y, como diferente de esto, algo que ama? EUTIFRÓN. ¿Cómo no?

SÓCRATES. Dime entonces, iacaso la cosa transportada es una cosa transportada porque es transportada, o por otra razón?

EUTIFRÓN. No, por esta misma razón.

SÓCRATES. ¿Y que una cosa es una cosa conducida porque es conducida, y una cosa es una cosa vista porque es vista?

EUTIFRÓN. Ciertamente.

SÓCRATES. Luego, la cosa no es vista porque es una cosa vista, sino, todo lo contrario, porque es vista es una cosa vista. Ni tampoco ella es conducida porque es una cosa conducida; más bien, porque es conducida es una cosa conducida. Ni tampoco es transportada porque es una cosa transportada; más bien, porque es transportada es una cosa transportada. ¿No es clarísimo, Eutifrón, lo que quiero decir? Quiero decir esto: que si alguna cosa deviene o le sucede algo, no deviene porque es una cosa que deviene, sino que porque deviene es una cosa que deviene; ni tampoco le sucede algo porque es una cosa a la que algo le sucede, sino que porque le sucede algo es una cosa a la que algo le sucede. ¿O no estás de acuerdo con esto?

EUTIFRÓN. Sí.

SÓCRATES. ¿No es también la cosa amada o una cosa que deviene o una cosa a la que algo le sucede por la acción de otro?

EUTIFRÓN. Claro.

SÓCRATES. ¿Acaso también ella se comporta de la misma manera que las anteriores: no es amada por quienes la aman porque es una cosa amada, sino que es una cosa amada porque es amada? EUTIFRÓN. Necesariamente.

SÓCRATES. ¿Qué decimos, entonces, acerca de lo piadoso, Eutifrón? ¿No es amado por los dioses todos, según tu argumento?

EUTIFRÓN. Sí.

SÓCRATES. ¿Por esta razón, porque es piadoso, o por otra?

EUTIFRÓN. No, por esta razón.

SÓCRATES. ¿Porque es piadoso es amado y no porque es amado es piadoso? EUTIFRÓN. Así parece. 
SÓCRATES. Por otro lado, ${ }^{19}$ es algo amado y agradable a los dioses porque es amado por los dioses.

EUTIFRÓN. Por supuesto.

SÓCRATES. Pues entonces lo agradable a los dioses no es lo piadoso, Eutifrón, ni tampoco lo piadoso es lo agradable a los dioses, como tú dices, sino que una cosa es distinta de la otra.

EUTIFRÓN. ¿Cómo así, Sócrates?

SÓCRATES. Porque convenimos en que lo piadoso es amado porque es piadoso, y no porque es amado es piadoso, io no?

EUTIFRÓN. Sí.

SÓCRATES. Pero lo agradable a los dioses, porque es amado por los dioses -es decir, por el mismo hecho de ser amado- es agradable a los dioses, y no porque es agradable a los dioses es amado.

EUTIFRÓN. Es verdad lo que dices.

SÓCRATES. No obstante, si fueran lo mismo, querido Eutifrón, lo agradable a los dioses y lo piadoso, entonces, si lo piadoso fuera amado por ser piadoso, también lo agradable a

Ila los dioses sería amado por ser agradable a los dioses; pero si, en cambio, lo agradable a los dioses fuera agradable a los dioses por ser amado por los dioses, también lo piadoso sería piadoso por ser amado por los dioses. Sin embargo, ahora observas que ambos se comportan de manera contraria, por ser dos cosas totalmente distintas entre sí. Pues lo uno $^{20}$, porque es amado, es tal como para ser amado; mientras que lo otro'1, porque es tal como para ser amado, es amado. Y parece, Eutifrón, que cuando se te pregunta qué es lo piadoso, no quieres ponerme de manifiesto su esencia (oủ $\sigma i ́ \alpha v$ ), sino que prefieres mencionar sobre ello un accidente ( $\pi \alpha \dot{\theta}$ os), algo que le ha sucedido a lo piadoso: ser amado por todos los dioses. Pero todavía no has dicho lo que es (ö $\tau \iota$ óv). Si es de tu agrado, por favor no me lo ocultes; más bien, dime nuevamente desde el comienzo qué es lo piadoso sin importar que sea amado por los dioses o que le suceda cualquier otra cosa -ya que no discreparemos sobre eso. Dime pues, con ánimo resuelto, iqué es lo piadoso y lo impío?

EUTIFRÓN. iPero, Sócrates, no encuentro la forma de decirte lo que pienso! Pues lo que sea que nos propongamos ( $\pi \varrho 0 \Theta \omega \mu \varepsilon \theta \alpha$ ), de alguna manera siempre da vueltas y no quiere permanecer donde lo asentemos.

SÓCRATES. Parece, Eutifrón, que las cosas dichas por ti son como las obras de mi antepasado Dédalo. Y si yo las hubiera dicho o propuesto, a lo mejor te estarías riendo de mí, puesto que también, conforme a mi parentesco con él, mis creaciones de palabra

\footnotetext{
19 El sujeto tácito sigue siendo lo piadoso.

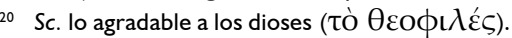

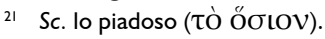


huyen y no quieren permanecer donde se las coloque ${ }^{22}$. Mas ahora sucede que son tuyas

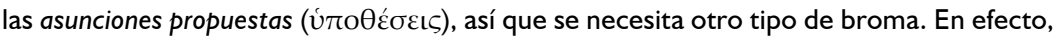
no quieren permanecerte quietas, tal como a ti mismo te parece.

EUTIFRÓN. Me da la impresión, Sócrates, de que a las cosas dichas les es necesaria casi la misma broma. Pues yo no soy el que les infunde esto de dar vueltas y no permanecer en el mismo sitio; más bien, creo que tú, tú eres el Dédalo, ya que si fuera por mí permanecerían quietas.

SÓCRATES. Entonces es probable, amigo, que a tal punto he resultado más hábil en este arte que mi venerable ancestro, que mientras él impedía que permanecieran quietas sus solas obras, yo he logrado -según parece- que, además de las mías, tampoco permanezcan quietas las ajenas. Y, sin duda, lo más exquisito de mi arte es que soy sabio sin quererlo; pues preferiría que mis afirmaciones permanecieran quietas y firmemente asentadas antes que llegar a tener, además de la sabiduría de Dédalo, las riquezas de Tántalo ${ }^{23}$. Bueno, ya basta de esto. Como tú me pareces un engreído, yo mismo uniré esfuerzos contigo para que me instruyas acerca de lo piadoso. iY no te me vayas a rendir tan pronto! Mira, pues, si no te parece necesario que todo lo piadoso sea justo. EUTIFRÓN. A mí sí. SÓCRATES. ¿Acaso también todo lo justo es piadoso? ¿O, más bien, todo lo piadoso es justo, pero no todo lo justo es piadoso -sino que una parte de ello es piadosa y otra algo distinto?

EUTIFRÓN. No puedo seguirle el paso a las cosas que dices, Sócrates. SÓCRATES. Y eso que eres más joven que yo no menos que cuanto eres más sabio; pero, como digo, eres un engreído por la riqueza de tu sabiduría. Ya, afortunado amigo,

22 La figura de los autómatas se remonta a Homero, donde Hefesto pasaba por ser el creador de piezas metálicas dotadas de movimiento propio: trípodes con ruedas de oro que penetraban en las juntas de los dioses y regresaban por sí solos a casa (cf. Ilíada, XVIII.373-7); perros inmortales de plata y oro destinados a ser guardianes del palacio de Alcínoo, rey de los feacios (cf. Odisea, VII.9l-4); y áureas sirvientas del dios "parecidas a muchachas con vida: tienen ellas sentido en sus entrañas y, asimismo, tienen fuerza y voz y, por don de los dioses inmortales, son duchas en artísticas labores” (Ilíada, XVIII.4I7-20). Dédalo, por lo visto, había logrado con sus 'estatuas' de madera el artificio de su patrono Hefesto; cf. Eurípides, fr. 372 (ed. Nauck):

\footnotetext{
"Nada de qué asustarse, viejo:

las obras de Dédalo aparentan todas andar y sus estatuas hablar, isabio hombre, aquél!"
}

23 Opulento rey asiático - de Frigia o Lidia, según las versiones. Por ser hijo suyo, Zeus lo había invitado a compartir la mesa con los dioses, pero luego Tántalo divulgó temerariamente los misterios divinos y repartió el néctar y la ambrosía entre sus compañeros. También se dice que cuando convidó un banquete a los dioses, les sirvió las carnes de su propio hijo con el fin de ponerlos a prueba. Estas y otras impiedades le valieron la condena a un suplicio eterno en el Hades (cf. Homrero, Odisea, XI.582-92). Permanecía sumergido hasta el mentón en las aguas de un lago y penaba de sed; cada vez que el anciano se agachaba a beber, el agua se escapaba absorbida. En torno suyo crecían árboles frondosos que asomaban sus frutos ante su frente, pero siempre que alargaba a ellos sus manos un torbellino arrebataba los frutales hasta las nubes. 
haz un mayor esfuerzo, pues ni siquiera es difícil comprender lo que digo. De hecho, quiero decir lo contrario de lo que quiso decir el poeta ${ }^{24}$ que compuso los versos:

Incluso el que ocasionó todo esto no se atreve a reprender a Zeus, quien lo hizo: pues ahí donde hay miedo hay también reverencia.

Así que yo discrepo de este poeta. ¿Quieres que te diga cómo? EUTIFRÓN. Por supuesto.

SÓCRATES. No me parece cierto que ahí donde hay miedo hay también reverencia. Pues me parece que muchos que les temen a las enfermedades, a la pobreza y a muchas otras cosas por el estilo, efectivamente experimentan miedo, pero de ningún modo reverencian las cosas que temen. ¿No te parece a ti también?

EUTIFRÓN. Seguro que sí.

SÓCRATES. En cambio, ahí donde hay reverencia hay también miedo. Porque quienquiera que reverencie algún hecho y se avergüence ante él, ¿acaso no siente al mismo tiempo miedo y teme una reputación de perversidad?

EUTIFRÓN. Claro que la teme.

SÓCRATES. Luego, no es correcto decir: pues ahí donde hay miedo hay también reverencia, sino, más bien, ahí donde hay reverencia hay también miedo -pues ciertamente la reverencia no está en todo lugar en el que el miedo se encuentre. Según creo, el miedo es más amplio que la reverencia. Ya que la reverencia es una parte del miedo, tal como lo impar lo es del número -de modo que ahí donde está el número no está también lo impar, sino que donde está lo impar está también el número. ¿Me sigues ahora?

EUTIFRÓN. Desde luego.

SÓCRATES. Algo parecido te estaba dando a entender entonces al preguntarte si acaso ahí donde está lo justo está también lo piadoso, o, más bien, ahí donde está lo piadoso está también lo justo, mientras que lo piadoso no está en todo lugar en el que lo justo se encuentre -pues lo piadoso es una parte de lo justo. ¿Lo diremos así o te parece que de otra manera?

EUTIFRÓN. No, así, ya que me parece que hablas correctamente.

SÓCRATES. Bien, observa lo siguiente. Si lo piadoso es una parte de lo justo, es necesario, según parece, que nosotros descubramos qué clase de parte de lo justo sería lo piadoso. En ese sentido, si tú me preguntaras por alguna de las cosas de ahora, por ejemplo, qué clase de parte del número es lo par y cuál resulta ser este número, yo diría: 'aquel que no sea escaleno, sino isósceles' 25 . ¿O no te parece?

24 Estasino de Chipre, presunto autor de las Ciprias (fr. 20, ed. Kinkel), poema épico del ciclo troyano que canta los sucesos anteriores a la llíada.

25 Esta definición del número par y del impar es única en la literatura griega conservada. A primera vista, puede parecer que nos encontramos ante una traslación de terminología geométrica al campo de la aritmética. 
EUTIFRÓN. Me da la impresión.

SÓCRATES. De la misma forma, intenta tú enseñarme qué clase de parte de lo justo es lo piadoso, a fin de que podamos decirle también a Meleto que nunca más cometa una injusticia contra nosotros ni nos denuncie por impiedad, dado que ya hemos aprendido suficientemente de parte tuya las cosas piadosas y religiosas, y las que no lo son. EUTIFRÓN. En efecto, esto me parece, Sócrates: que la parte de lo justo referida al cuidado de los dioses es piadosa y religiosa, mientras que la referida al cuidado de los hombres es la parte restante de lo justo.

SÓCRATES. Y me parece que hablas bien, Eutifrón, pero todavía me veo necesitado de

13a un poco más. De hecho, aún no comprendo a qué le das el nombre de 'cuidado'

$(\theta \varepsilon \varrho \alpha \pi \varepsilon i ́ \alpha v)$. Seguro que no te refieres a que, tal como hay precisamente cuidados referidos a otras cosas, así también existe uno similar relativo a los dioses - pues solemos

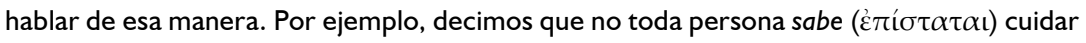
a los caballos, pero sí el especialista en equitación, ¿o no?

EUTIFRÓN. Ciertamente.

SÓCRATES. Y que el cuidado de los caballos es la equitación. EUTIFRÓN. Sí.

SÓCRATES. Ni tampoco toda persona sabe cuidar a los perros, pero sí el especialista en cinegética.

EUTIFRÓN. Así es.

SÓCRATES. Y que el cuidado de los perros es la cinegética.

b EUTIFRÓN. Sí.

SÓCRATES. Y que el cuidado de los bueyes es la ganadería.

EUTIFRÓN. Ciertamente.

SÓCRATES. ¿Entonces el cuidado de los dioses es la religión y la piedad, Eutifrón?

¿Quieres decir algo así?

EUTIFRÓN. Claro.

SÓCRATES. ¿Acaso no todo cuidado logra lo mismo? Algo como esto: apunta a cierta excelencia y al beneficio de lo cuidado, tal como observas que los caballos cuidados por la equitación son beneficiados y se vuelven mejores. ¿O no te parece?

EUTIFRÓN. Seguro.

SÓCRATES. Igual con los perros cuidados por la cinegética y los bueyes cuidados por la ganadería y, de la misma manera, todas las demás cosas. ¿O crees que el cuidado apunta al perjuicio de lo cuidado?

EUTIFRÓN. No, por Zeus.

En efecto, aún hoy seguimos llamando isósceles al triángulo que consta de dos lados iguales y escaleno a aquel cuyos tres lados son desiguales. Pero, etimológicamente, isósceles significa 'de piernas iguales', por lo que resulta una definición adecuada para todo número par, divisible en dos partes iguales; mientras que escaleno significa 'desigual, escabroso', porque si bien todo número impar (descontada la unidad, que para los griegos no era impar ni par) es divisible en más de dos partes iguales (v.g. $3=1+I+I)$, ninguno lo es en dos números enteros iguales. 
SÓCRATES. ¿Pero sí a su beneficio?

EUTIFRÓN. ¿Cómo no?

SÓCRATES. Y siendo la piedad el cuidado de los dioses, iacaso es para los dioses un beneficio y hace mejores a los dioses? ¿También tú concederías esto, que, cuando realizas algo piadoso, logras hacer mejor a alguno de los dioses?

EUTIFRÓN. No, por Zeus, de ninguna manera.

SÓCRATES. Tampoco yo creo, Eutifrón, que tú quieres decir eso -estoy lejos de ello-, sino que por esta razón te pregunté a qué te referías con el cuidado de los dioses, sin creer que te referías a uno de ese tipo.

EUTIFRÓN. Y correctamente, Sócrates, pues no me refiero a uno de ese tipo.

SÓCRATES. Bueno, ientonces qué clase de cuidado de los dioses sería la piedad?

EUTIFRÓN. Aquel cuidado, Sócrates, que los esclavos rinden a sus amos.

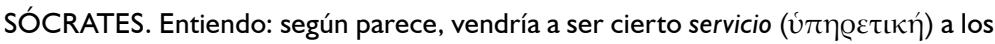
dioses ${ }^{26}$.

EUTIFRÓN. Por supuesto.

SÓCRATES. Podrías decirme... iel servicio a los médicos es un servicio que apunta hacia la producción de qué obra? ¿No crees que hacia la de la salud?

EUTIFRÓN. Claro.

e SÓCRATES. ¿Qué hay del servicio a los constructores navales? ¿Es un servicio que apunta hacia la producción de qué obra?

EUTIFRÓN. Es evidente, Sócrates, que hacia la de un barco.

SÓCRATES. ¿Y, seguro, el servicio a los arquitectos hacia la de una casa? EUTIFRÓN. Sí.

SÓCRATES. Dime, mi estimado, ¿el servicio a los dioses sería un servicio que apunta hacia la producción de qué obra? Es evidente que tú sabes, ya que precisamente afirmas que, de entre los hombres, tú eres el que mejor sabe los asuntos divinos.

EUTIFRÓN. Y lo que digo es verdad, Sócrates.

SÓCRATES. Entonces dime, por Zeus, ¿cuál es aquella excelente obra ( $\pi \alpha ́ \gamma \kappa \alpha \lambda$ ov ع́Q $\gamma o v)$ que los dioses producen utilizándonos a nosotros como servidores?

EUTIFRÓN. Muchas y bellas obras, Sócrates.

14a SÓCRATES. Pero también los jefes militares, mi amigo. Sin embargo, fácilmente me podrías decir la principal de ellas: que producen la victoria en la guerra, ¿o no?

EUTIFRÓN. ¿Cómo no?

SÓCRATES. También los campesinos, creo, producen muchas y bellas obras. No obstante, lo fundamental de su producción consiste en el alimento obtenido de la tierra. EUTIFRÓN. Ciertamente.

26 Cf. Platón, Apología, 30a: "Pues esto lo ordena el dios, sépanlo bien, y yo creo que aún no les ha sucedido a ustedes mayor bien en la ciudad que mi servicio al dios ( $\tau \tilde{\omega} \theta \varepsilon \tilde{\omega} u ́ t \eta \emptyset \varepsilon \sigma i ́ \alpha v)$. En efecto, voy por todas partes sin hacer otra cosa que persuadirlos a ustedes, jóvenes y viejos, a no cuidar ni sus cuerpos ni sus riquezas con tanta insistencia antes que cuidar el alma para que ésta sea lo mejor posible". 
SÓCRATES. ¿Qué hay de las muchas y bellas obras que los dioses producen? ¿Qué es lo fundamental de su producción?

EUTIFRÓN. Poco antes te dije que es una tarea difícil, Sócrates, aprender con exactitud cómo son todas estas cosas. Sin embargo, te voy a decir lo siguiente de una manera sencilla: que en el caso de que alguien sepa ( $(\dot{\pi} i ́ \sigma \tau \eta \tau \alpha \iota)$ hacer y decir las cosas que complacen a los dioses, suplicando y sacrificando ${ }^{27}$, ésas son acciones piadosas, y actos de ese tipo salvan a las familias y a los Estados; mientras que las cosas contrarias a las que les complacen son impías, y traen abajo y arruinan todo.

SÓCRATES. Si lo hubieras querido, Eutifrón, sin duda me habrías podido contestar, con mucha mayor brevedad, lo fundamental de lo que te preguntaba. Pero no estás animado a enseñarme -es clarísimo. Puesto que ahora, cuando estabas cerca de ello, te apartaste; si lo hubieras contestado, ya habría aprendido de ti la piedad suficientemente. Ahora, en cambio, es necesario que el que pregunta siga al interrogado por donde él lo guíe. De nuevo, ¿qué dices que es lo piadoso y la piedad? ¿No consiste en cierto conocimiento

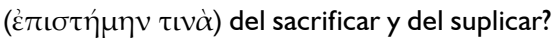

EUTIFRÓN. Efectivamente.

SÓCRATES. ¿No consiste el sacrificar en dar ofrendas a los dioses y el suplicar en pedir a los dioses?

EUTIFRÓN. Precisamente, Sócrates.

SÓCRATES. Entonces, según este argumento, la piedad sería un conocimiento de la petición y de la ofrenda a los dioses ${ }^{28}$. EUTIFRÓN. Muy bien, Sócrates, comprendiste lo que dije.

SÓCRATES. Sí, estoy deseoso de tu sabiduría, amigo, y le presto atención para que no se

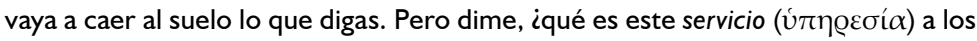
dioses? ¿Dices que consiste en pedirles y darles?

EUTIFRÓN. Claro.

SÓCRATES. ¿Acaso no consistiría el correcto pedir en pedirles a ellos las cosas que necesitamos de su parte?

EUTIFRÓN. ¿Qué otra cosa si no?

e SÓCRATES. A su vez, ino consistiría el correcto dar en ofrendarles a cambio las cosas que resultan necesitar de nosotros? De hecho, no sería un ofrendar muy experto ( $\tau \varepsilon \chi \nu \iota \kappa o ́ v)$ que digamos que alguien le dé a otro las cosas que no necesita.

\footnotetext{
27 Véase la admonición a Aquiles en la llíada (IX.497-50I): “Ya que aun los dioses mismos son flexibles, de los cuales la virtud, la gloria y la fuerza son mayores que las tuyas; también a ellos con sacrificios y amables súplicas, con incienso y libaciones, los hombres, implorándoles, disuaden, cuando alguno ha cometido o una transgresión o una falta". Por razones morales, estos versos no escaparon a la censura de Platón en la República (364d-e).

28 "La clase de los sacerdotes, como dicta la costumbre, es experta en ambas cosas: de parte nuestra, sabe dar ofrendas a los dioses por medio de sacrificios, según el gusto de éstos; $y$, de parte de los dioses, saber pedir para nosotros la adquisición de bienes por medio de súplicas" (Platón, Político, 290c-d).
} 
EUTIFRÓN. Es verdad lo que dices, Sócrates.

SÓCRATES. Por lo tanto, Eutifrón, la piedad sería un mutuo arte comercial ( $\dot{\varepsilon} \mu \pi$ To@kì $\tau \varepsilon ́ \chi \vee \eta)$ entre dioses y hombres.

EUTIFRÓN. Comercial ${ }^{29}$, si te es más placentero llamarlo así.

SÓCRATES. Para nada me es más placentero, si no resulta ser verdadero. Bueno, cuéntame: ¿cuál resulta ser el beneficio para los dioses a partir de los dones que reciben de nosotros? Pues para cualquiera son evidentes las cosas que ellos dan, ya que nosotros no tenemos ningún bien que ellos no nos den. ¿Pero por qué son beneficiados por las cosas que reciben de nosotros? ¿O, más bien, a tal punto sacamos mayor provecho que ellos en nuestro comercio, que recibimos todos los bienes de parte suya y ellos nada de parte nuestra?

EUTIFRÓN. ¿Acaso crees, Sócrates, que los dioses son beneficiados por las cosas que reciben de nosotros?

SÓCRATES. Pero, Eutifrón, ¿cuáles serían los dones a los dioses de parte nuestra? EUTIFRÓN. ¿No crees que nada menos que honor, homenajes y, como decía hace poco, complacencia?

SÓCRATES. ¿Entonces lo que les complace es lo piadoso, Eutifrón, y no lo beneficioso ni lo agradable a los dioses?

EUTIFRÓN. Yo creo que sobre todo lo agradable.

SÓCRATES. Luego, esto, según parece, es otra vez lo piadoso: lo agradable a los dioses. EUTIFRÓN. Precisamente.

SÓCRATES. ¿Te sorprenderás diciendo estas cosas en el caso de que tus afirmaciones no aparezcan quietas sino caminando, y me echarás la culpa a mí, al Dédalo, porque las hago caminar, siendo tú mismo mucho más hábil que Dédalo y el que las hace dar vueltas en círculo? ¿O no te das cuenta de que nuestro argumento, dando la vuelta, ha llegado otra vez a lo mismo? Seguro recuerdas que anteriormente lo piadoso y lo que los dioses aman no nos parecieron lo mismo sino distintos entre sí, io no lo recuerdas?

EUTIFRÓN. Claro.

SÓCRATES. Ahora, ino te das cuenta de que afirmas que lo agradable a los dioses es lo piadoso? ¿Acaso eso no viene a ser lo que los dioses aman?

EUTIFRÓN. Desde luego.

SÓCRATES. Por consiguiente, o antes no nos pusimos muy bien de acuerdo, o, si en ese momento lo hicimos bien, ahora estamos proponiendo algo incorrecto.

EUTIFRÓN. Así parece.

SÓCRATES. Entonces, de nuevo tenemos que examinar desde el comienzo qué es lo piadoso, dado que yo no voy a acobardarme adrede antes de que lo aprenda. Pero no me

29 No deja de ser curioso que en el pórtico del arconte-rey -el edificio público ante el que se desarrolla la presente conversación-se exhibía el calendario ateniense de sacrificios, el cual consignaba los precios de las ofrendas correspondientes a cada dios. 


\section{Platón}

desprecies, sino que prestando tu atención al máximo por todos los medios, cuéntame ahora la verdad. Pues si alguien de entre los hombres sabe, ése eres tú, $y$, al igual que Proteo ${ }^{30}$, no serás liberado hasta que me cuentes. Puesto que si no hubieras sabido claramente lo piadoso y lo impío, no hay manera de que hubieras intentado jamás procesar por homicidio a tu anciano padre en nombre de un jornalero, sino que habrías temido arriesgarte a no realizar esto correctamente a los ojos de los dioses y te habrías sentido avergonzado ante los hombres. Ahora, yo sé muy bien que tú crees saber claramente lo piadoso y lo que no lo es. Dímelo, mi excelente Eutifrón, y no me ocultes lo que a eso consideras.

EUTIFRÓN. Será para otra ocasión, Sócrates, pues ahora tengo prisa y es hora de irme. SÓCRATES. ¿iQué cosa haces, amigo!? Te vas derribándome de la gran esperanza que tenía de que, una vez que aprendiera de ti las cosas piadosas y las que no lo son, me fuera

16a a librar de la acusación de Meleto -mostrándole así que por fin me he vuelto un sabio en los asuntos divinos gracias a Eutifrón, que ya no hablo temerariamente por mi ignorancia ni presento innovaciones en relación con ellos, y que, sobre todo, voy a vivir mejor el resto de mi vida.

30 Proteo ("el infalible viejo del mar") era un siervo de Poseidón que, como divinidad marina, era capaz de predecir el futuro y de asumir múltiples figuras al verse en apuros. Cuando el rey Menelao se ve retenido en arenas egipcias, la diosa Eidotea, hija de Proteo, le aconseja apresar con violencia a su padre aunque cambie varias veces de forma: sólo al regresar a su figura original le podría referir su destino (cf. Homero, Odisea, IV.35I-480). Según Sócrates, Eutifrón se asemeja a Proteo no sólo en su rol de adivino sino también en las diversas metamorfosis que han sufrido sus respuestas. 